\title{
Echocardiographic findings in persistent truncus arteriosus in a young adult
}

Premindra A. N. Chandraratna, Udayan Bhaduri, Benjamin B. Littman, and Frank J. Hildner With the technical assistance of Dale Gindlesperger

From the Division of Cardiology, Department of Medicine, Mount Sinai Medical Center, Miami Beach, Florida, U.S.A.

The clinical, haemodynamic, and echocardiographic features of persistent truncus arteriosus in a young adult are presented. Several echocardiographic abnormalities were observed, namely ( $I$ ) diastolic fluttering of the anterior mitral leaflet, (2) dilatation of the 'aortic' root, (3) four 'aortic' valve cusp echoes, (4) separation of the 'aortic' cusps during diastole, (5) dilatation of the right ventricle with paradoxical motion of the septum, (6) the anterior wall of the 'aorta' was anterior to the septum and the posterior 'aortic' wall posterior to the closed position of the mitral valve.

The significance of these findings is discussed.

Since the introduction of echocardiography in 1954 by Edler and Hertz (1954), several workers have confirmed its usefulness in the evaluation of patients with valvular heart disease (Joyner and Reid, 1963; Joyner et al., 1967; Gramiak and Shah, 1970). More recently this technique has been found to be a valuable aid in the diagnosis of congenital heart disease. Characteristic findings have been described in atrial septal defect (Diamond et al., 197I), Ebstein's anomaly (Lundstrom, 1973), double outlet right ventricle (Chesler et al., 197I), transposition of the great arteries (Gramiak et al., 1973), and tetralogy of Fallot (Chung et al., 1973).

Patients with truncus arteriosus usually present with cardiac failure and cyanosis during the neonatal period. Survival to adult life is rare (Tandon, Hauck, and Nadas, I963). In this report we describe the haemodynamic and echocardiographic features of truncus arteriosus with associated ventricular septal defect, atrial septal defect, and incompetence of the truncal valve, in a 2I-year-old woman.

\section{Case report}

A 21-year-old white woman was admitted to Mount Sinai Hospital in March 1973. She was noted to be cyanotic at birth, and she had had fatigue and dyspnoea since childhood. She had been subject to frequent respiratory infections in the past. There was no history of squatting, syncope, chest pain, or palpitations. Two years before admission she was seen at another hospital with mild cardiac failure and was started on digitalis and diuretic therapy. Several phlebotomies were performed in order to correct her polycythaemia. Her symptoms gradually increased, and at the time of admission she had dyspnoea on walking a short distance on the level. There was no family history of congenital heart disease.

On examination she was a thin, underdeveloped woman, $145 \mathrm{~cm}$ in height and $35 \mathrm{~kg}$ in weight. There was pronounced cyanosis and clubbing of her fingers and toes. The peripheral pulses were normal and peripheral oedema was not present. Her blood pressure was I $10 / 70 \mathrm{mmHg}$, and she was in normal sinus rhythm with a heart rate of 80 a minute. The venous pressure was not raised, and the apex beat was in the sixth interspace, I cm outside the midclavicular line. A systolic thrill and a right ventricular lift were present at the left sternal border. A loud ejection click and grade $4 / 6$ ejection systolic murmur were heard at the base. A grade $4 / 6$ holodiastolic blowing murmur was present at the left sternal edge. The second sound was closely split; this finding was confirmed by phonocardiography. Her lungs were clear. The abdomen and central nervous system were clinically normal.

The electrocardiogram showed sinus rhythm, right axis deviation (axis plus $120^{\circ}$ ), and biventricular hypertrophy. The chest $x$-ray showed a boot-shaped heart, with dilatation of the ascending 'aorta' and absence of the main pulmonary artery segment. The pulmonary vascular markings were slightly increased, and there was no valvular calcification on fluoroscopy.

Echocardiography was performed with the patient supine, and the transducer was placed in the third intercostal space, I cm from the left sternal edge. Fine diastolic fluttering of the anterior mitral leaflet was seen 


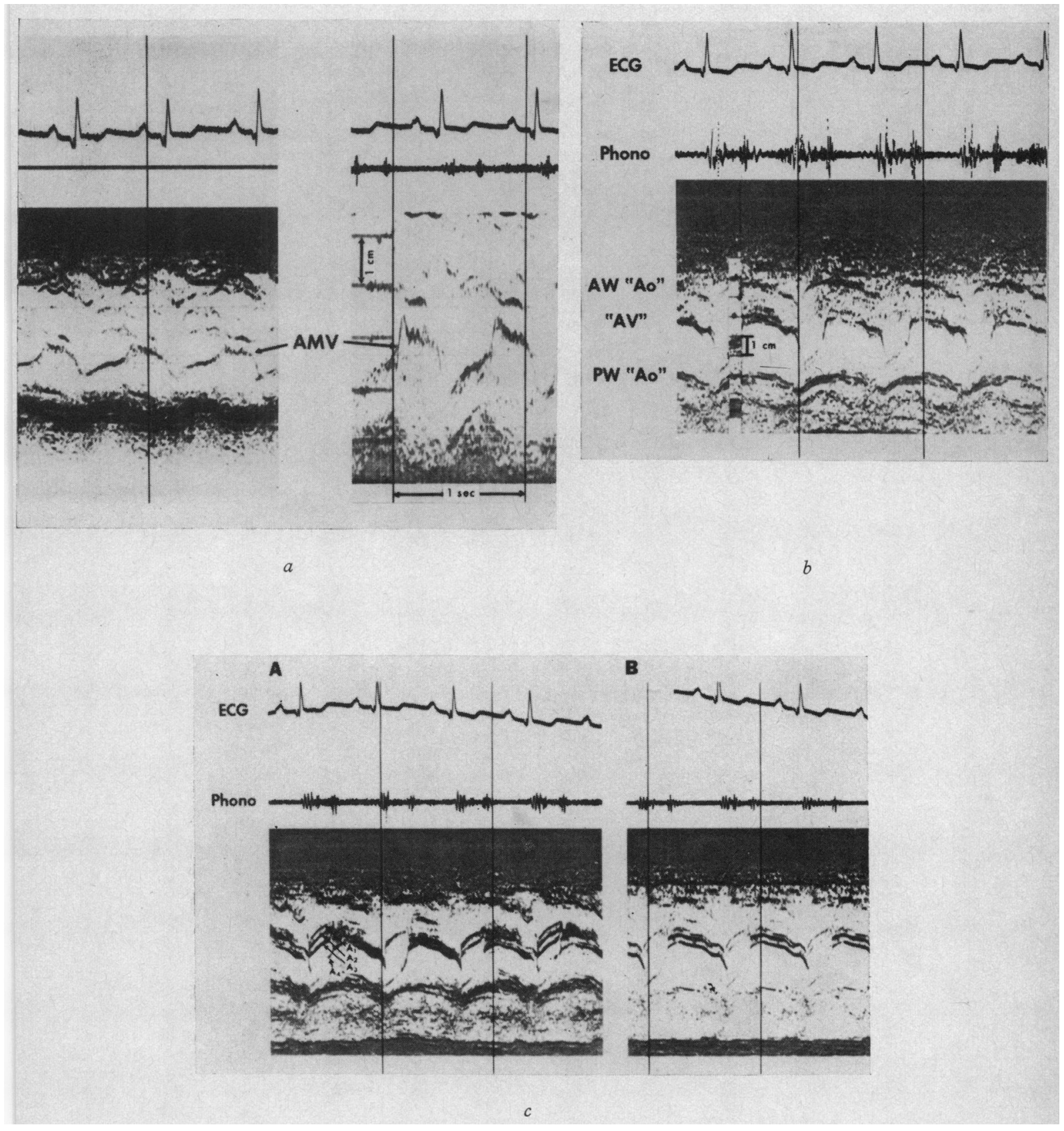

FIG. I Echocardiograms of the valves. a) Echocardiogram of the anterior mitral leaflet showing diastolic fluttering of the valve. The right panel is a blow-up which demonstrates the fluttering more clearly. b) Echocardiogram of the 'aortic root' (truncus). The 'aortic (truncal) valve' (' $A V$ ') is seen. Phono= Phonocardiogram, $A W$ ' $A o^{\prime}$ '=anterior wall of 'aorta', $P W$ ' $A o^{\prime}$ ' = posterior wall of 'aorta'. c) Echocardiogram of the 'aortic' (truncal) valve. Four cusp echoes are seen ( $\left.A_{1}, A_{2}, A_{3}, A_{4}\right)$. There is abnormal separation of the cusps in diastole (Panel $\left.B\right)$. 


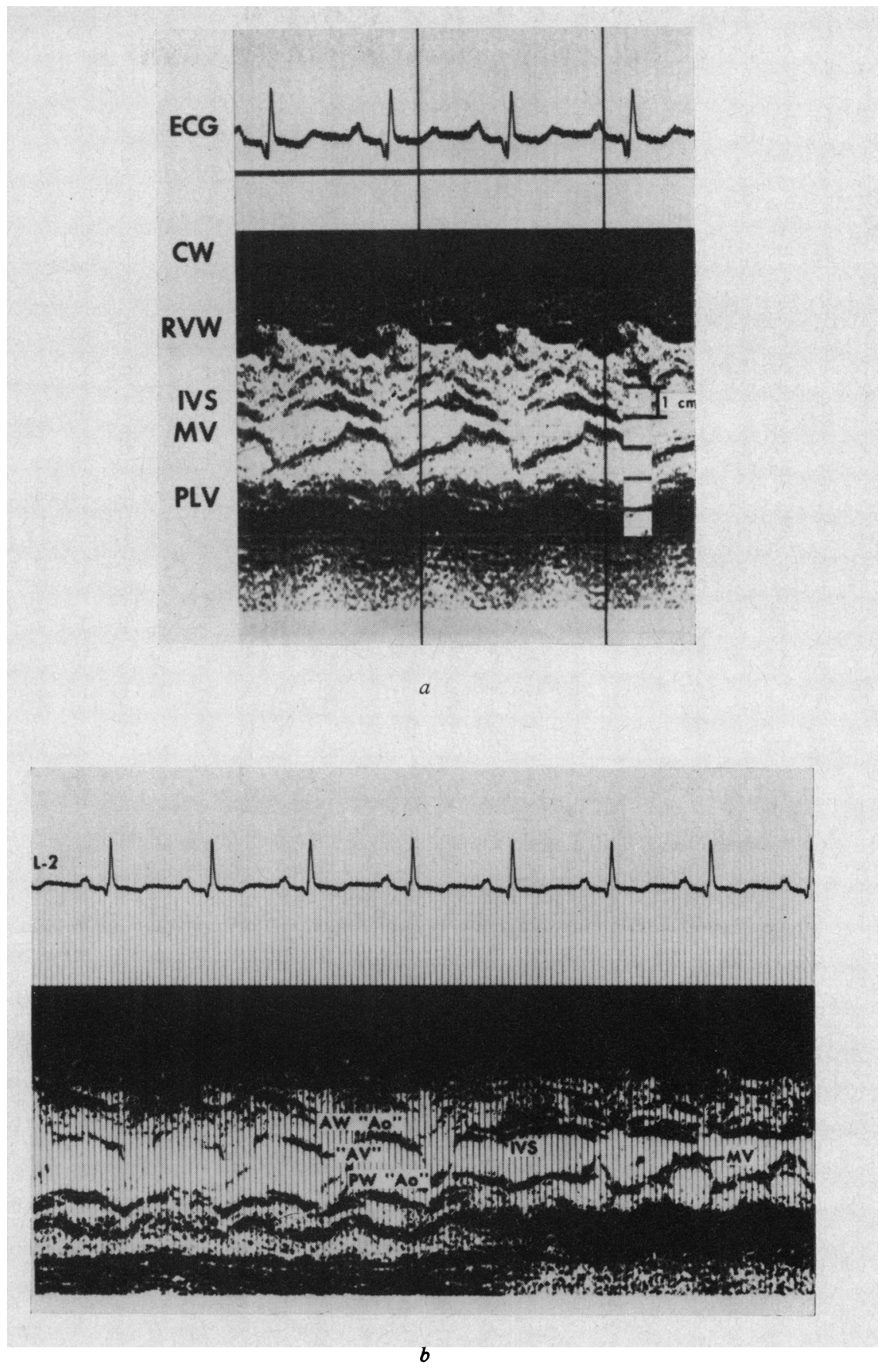

FIG. 2 Echocardiograms of the ventricular septum. a) The right and left ventricles are shown. Paradoxical motion of the septum (IVS) is evident. CW =chest wall; $R V W=$ anterior wall of right ventricle; $M V=$ anterior mitral leaflet; $P L V=$ posterior wall of left ventricle. $b)$ The relation between the 'aortic' root (truncus), the interventricular septum (IVS), and the mitral valve (MV). $A W$ ' $A o^{\prime}$ ' = anterior wall of 'aorta'; $P W$ ' $A o^{\prime}$ '= posterior wall of 'aorta'; $A V=$ 'Aortic' valve. 
Fig. Ia). The 'aortic root' (truncus) was grossly dilated and it was $4.6 \mathrm{~cm}\left(3.9 \mathrm{~cm} / \mathrm{m}^{2}\right)$ in diameter (Fig. Ib). (Upper limit of normal is $3.7 \mathrm{~cm}$ or $2.2 \mathrm{~cm} / \mathrm{m}^{2}$ ) (Feigenbaum, 1972). Four aortic valve (truncal valve) cusp echoes were seen during systole (Fig. Ic). There was incomplete apposition or separation of the valve cusps during diastole (Fig. IC). The maximal separation of the valve cusps during systole was $2.5 \mathrm{~cm}$ (normal $\mathrm{I} \cdot 6$ $2.6 \mathrm{~cm}$ ) (Feigenbaum, 1972). The right ventricle (Fig. 2a) was dilated and measured $3.3 \mathrm{~cm}$ or $2.7 \mathrm{~cm} / \mathrm{m}^{2}$ (upper limit of normal $2.3 \mathrm{~cm}$ or $1.2 \mathrm{~cm} / \mathrm{m}^{2}$ ) (Feigenbaum, 1972). The interventricular septum showed paradoxical motion (anterior motion during systole).

Fig. 2b shows the relation between the 'aortic root' and the interventricular septum. This was achieved by angling the transducer from an initial medial and superior position to a lateral and inferior position. In the normal heart the anterior wall of the aorta is continuous with the septum, and the posterior wall is continuous with the closed position of the mitral valve. In our patient the anterior wall of the 'aorta' is anterior to the septum. Thus, the 'aorta' overrides the septum. The posterior wall of the 'aorta' is posterior to the closed position of the mitral valve. However, there appears to be continuity between the aortic valve (in the open position) and the mitral valve (in the closed position). Tricuspid valve movement did not show any obvious abnormality.

Right and left heart catheterization, 9 days after she was admitted, showed a right atrial mean pressure of $4 \mathrm{mmHg}$ and a right ventricular pressure of $132 / 8 \mathrm{mmHg}$. The pressure in the 'aorta' was $132 / 87 \mathrm{mmHg}$ with a mean of $115 \mathrm{mmHg}$, and the left ventricular pressure was $132 / 1 \mathrm{I} \mathrm{mmHg}$. The pulmonary artery was not entered. During right heart catheterization the left atrium was entered via an atrial septal defect. The mixed venous oxygen saturation was 59 per cent and there was no oxygen step-up in the right ventricle. The oxygen saturation in the pulmonary vein was 97 per cent, left atrium 90 per cent, left ventricle 7 I per cent, and femoral artery 67 per cent.

A right ventricular angiogram showed filling of the 'aorta' and the left ventricle, but the pulmonary arteries were not visualized. 'Aortic root' injection showed pronounced dilatation of the 'ascending aorta', moderate 'aortic' regurgitation, and three 'aortic valve' cusps were identified. The main pulmonary artery arose from the posterior aspect of the ascending 'aorta'. The angiographic findings were suggestive of Type II truncus arteriosus (Tandon et al., 1963; Collett and Edwards, 1949; Van Praagh and Van Praagh, 1965).

\section{Discussion}

The physical signs, chest $x$-ray, and angiograms in our patient are typical of truncus arteriosus. A ventricular septal defect is invariably associated with this anomaly (Van Praagh and Van Praagh, 1965) and incompetence of the truncal valve is not uncommon (Tandon et al., 1963).

Several echocardiographic abnormalities were noted. Diastolic fluttering of the mitral valve was probably due to truncal valve incompetence. This finding helped to identify the holodiastolic murmur as being of 'aortic' origin as opposed to being due to a pulmonary incompetence which may be associated with an Eisenmenger ventricular or atrial septal defect. The 'aortic root' was very dilated. Though dilatation of the ascending aorta occurs in tetralogy of Fallot, this degree of enlargement is probably more in favour of truncus arteriosus. Another unusual feature was the recording of four echoes from the aortic valve cusps. There are several possible explanations for this. Multiple echoes from the valve cusps have been described in calcific aortic stenosis (Gramiak and Shah, 1970). Against this are the absence of 'aortic' calcification on fluoroscopy, the absence of an 'aortic' valve gradient, and the systolic separation of the valve cusps of $2.5 \mathrm{~cm}$, which is in the upper normal range, whereas in a calcified aortic valve the mobility of the cusps is diminished, and, therefore, the systolic separation is less than normal. Two anatomical features of the semilunar valve in truncus arteriosus deserve comment. Calder and associates (I97I) observed that the truncal valve faces anteriorly and leftward as opposed to the orientation of the normal aortic valve. Van Praagh and Van Praagh (1965) described thick, fleshy polypoid truncal leaflets as being a frequent occurrence. These abnormalities may help to explain multiple 'aortic' valve echoes. The four cusp echoes may also be explained on the basis of four truncal leaflets. The angiogram, however, showed only three leaflets, though this does not completely exclude the presence of a fourth cusp. Splitting of the second sound which was observed in our patient raises the possibility of the presence of more than three cusps, as suggested by Tandon and associates (1963). The lack of apposition of the 'aortic' valve cusps during diastole may explain the 'aortic' incompetence that was seen in our patient. Feigenbaum (1972) made a similar observation in a patient with truncus arteriosus.

The dilatation of the right ventricle and paradoxical movement of the septum suggest volume overloading of the right ventricle. The absence of an oxygen step-up in the right heart precludes a significant left-to-right shunt at atrial or ventricular level at the present time. Truncal valve incompetence is another cause of right ventricular volume overload in our patient. Selective streaming of blood is a possible explanation for the absence of an oxygen step-up in the right ventricle, in the presence of truncal valve incompetence. The much increased right ventricular pressure probably contributed to the dilatation of the right ventricle but paradoxical septal motion is not a feature of right ventricular pressure overload (Feigenbaum, 1972). 
The anterior wall of the 'aorta' was anterior to the septum, indicating that there was overriding of the aorta. This also occurs in tetralogy of Fallot. Chung and associates (1973) observed that in patients with tetralogy the posterior wall of the aorta was either continuous with or anterior to the closed position of the mitral valve; whereas in our patient the posterior 'aortic' wall was posterior to the mitral valve. In double outlet right ventricle, on the other hand, there is discontinuity between the closed position of the mitral valve and the posterior wall of the aorta, but the septum is continuous with the anterior aortic wall (Chesler et al., 1971).

In summary, several echocardiographic abnormalities were noted in a 2 I-year-old woman with persistent truncus arteriosus. Though some of these observations are not specific for this defect, the combination of findings may provide useful clues to the diagnosis of this anomaly.

\section{References}

Calder, A. L., Van Praagh, R., Van Praagh, S., and Sears, W. P. (1971). Diagnosis of truncus arteriosus (abstract). Circulation, 44, Suppl. II, 148.

Chesler, E., Joffe, H. S., Beck, W., and Schrire, V. (I97I). Echocardiographic recognition of mitral-semilunar valve discontinuity. Circulation, 43, 725 .

Chung, K. J., Nanda, N. C., Manning, J. A., and Gramiak, R. (1973). Echocardiographic findings/ in tetralogy of Fallot (abstract). American fournal of Cardiology, 31, 126.
Collett, R. W., and Edwards, J. E. (1949). Persistent truncus arteriosus: a classification according to anatomic types. Surgical Clinics of North America, 29, 1245.

Diamond, M. A., Dillon, J. C., Haine, C. L., Chang, S., and Feigenbaum, H. (1971). Echocardiographic features of atrial septal defect. Circulation, 43, I29.

Edler, I., and Hertz, C. H. (1954). Use of ultrasonic reflectoscope for the continuous recording of movements of heart walls. Kungliga Fysiografiska Sällskapets $i$ Lund Förhandlingar, 24, 5.

Feigenbaum, H. (1972). Echocardiography, pp. 137, 196, and 216. Lea and Febiger, Philadelphia.

Gramiak, R., Chung, K. J., Nanda, N., and Manning, J. (1973). Echocardiographic diagnosis of transposition of the great vessels. Radiology, 106, 187 .

Gramiak, R., and Shah, P. M. (1970). Echocardiography of the normal and diseased aortic valve. Radiology, 96, I.

Joyner, C. R., Hey, E. B., Jr., Johnson, J., and Reid, J. M. (1967). Reflected ultrasound in the diagnosis of tricuspid stenosis. American fournal of Cardiology, 19, 66.

Joyner, C. R., and Reid, J. M. (1963). Applications of ultrasound in cardiology and cardiovascular physiology. Progress in Cardiovascular Diseases, 5, 482.

Lundstrom, N. R. (1973). Echocardiography in the diagnosis of Ebstein's anomaly of the tricuspid valve. Circulation, 47, 597.

Tandon, R., Hauck, A. J., and Nadas, A. S. (1963). Persistent truncus arteriosus. Circulation, 28, I050.

Van Praagh, R., and Van Praagh, S. (1965). The anatomy of common aorticopulmonary trunk (truncus arteriosus communis) and its embryologic implications. American fournal of Cardiology, 16, 406.

Requests for reprints to Dr. P. A. N. Chandraratna, Cardiology Unit, Mount Sinai Medical Center, 4300 Alton Road, Miami Beach, Florida 33140, U.S.A. 